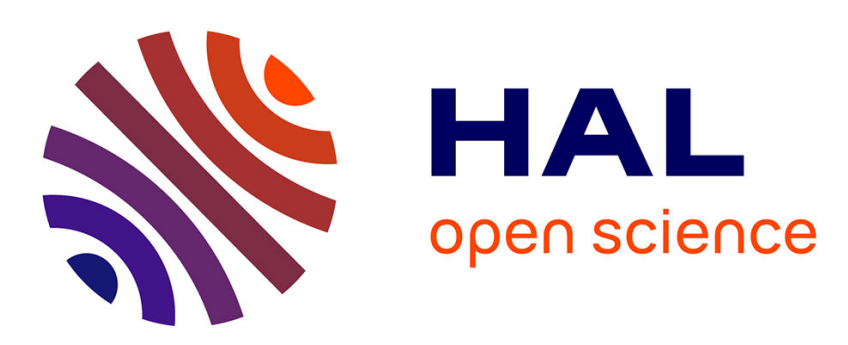

\title{
Dominant radial and height growth reveal comparable historical variations for common beech in north-eastern France
}

Jean-Daniel Bontemps, Jean-Christophe Hervé, Jean-François Dhôte

\section{- To cite this version:}

Jean-Daniel Bontemps, Jean-Christophe Hervé, Jean-François Dhôte. Dominant radial and height growth reveal comparable historical variations for common beech in north-eastern France. Forest Ecology and Management, 2010, 259 (8), pp.1455-1463. 10.1016/j.foreco.2010.01.019 . hal-01081192

\author{
HAL Id: hal-01081192 \\ https://hal.science/hal-01081192
}

Submitted on 7 Nov 2014

HAL is a multi-disciplinary open access archive for the deposit and dissemination of scientific research documents, whether they are published or not. The documents may come from teaching and research institutions in France or abroad, or from public or private research centers.
L'archive ouverte pluridisciplinaire HAL, est destinée au dépôt et à la diffusion de documents scientifiques de niveau recherche, publiés ou non, émanant des établissements d'enseignement et de recherche français ou étrangers, des laboratoires publics ou privés. 
DOMINANT RADIAL AND HEIGHT GROWTH REVEAL COMPARABLE HISTORICAL VARIATIONS FOR COMMON BEECH IN NORTH-EASTERN FRANCE

Jean-Daniel BONTEMPS ${ }^{\text {a,* }}$, Jean-Christophe HERVÉ ${ }^{b}$, Jean-François DHÔTE $^{c}$

a AgroParisTech, ENGREF, UMR 1092 INRA/AgroParisTech Laboratoire d'Etude des Ressources Forêt-Bois (LERFoB), 14 rue Girardet, 54000 Nancy, France

${ }^{\mathbf{b}}$ Inventaire Forestier National (IFN), Direction Technique, Domaine des Barres, 45290 Nogent-surVernisson, France

${ }^{\mathbf{c}}$ Office National des Forêts (ONF), Direction Technique et Commerciale Bois, Boulevard de Constance, 77300 Fontainebleau, France

*corresponding author: jdbontemps.agroparistech@gmail.com 


\begin{abstract}
While forest productivity is usually inferred from height growth indices, retrospective analyses of tree rings have been intensively used to assess long-term trends in forest productivity. However, radial growth is sensitive to the degree of competition between trees and influenced by management practices or local disturbances. Whether radial growth is accurate for diagnosing and quantifying productivity changes remains a debated question.

In a previous study, we assessed historical variations in dominant height growth of even-aged stands of common beech in north-eastern France as a proxy for their productivity changes. The analysis was based on a sampling design including 14 pairs of young/old (75/150 years) neighbour stands growing under the same site conditions. Dominant height was reconstructed from stem analyses and was compared between generations using a statistical modelling procedure.

In this analysis, we tested whether radial and height growth of dominant trees may provide compatible indications on long-term trends. We therefore measured and analysed the radial growth of dominant trees at breast height for the same sampled trees. The effects of site, developmental stage, and calendar date were separated by applying a similar modelling approach. Consideration of the developmental stage effect led to the formulation of an original growth equation.

Analysis of radial growth revealed: (i) a long-term positive increase; (ii) a magnitude of $+50 \%$ over the last century; and (iii) growth declines in the 1940s and 1990s. These features were remarkably similar to those reported on dominant height, and indicated that radial growth of dominant trees delivered a sound picture of productivity changes. The radial growth chronology also differed by showing a more acute acceleration phase in the early century, and a recent but significant difference between stand generations.
\end{abstract}

Keywords: Growth trends; Radial growth; Dominant trees; Statistical modelling; Mixed-effects models; Fagus sylvatica 


\section{INTRODUCTION}

In temperate and northern ecosystems, tree rings are easy to sample and measure, and provide quantitative information on past annual tree growth. Therefore, radial growth has been widely used to investigate forest productivity and vitality in the field of dendrochronological studies. The approach has been a predominant contributor to the issue of long-term growth trends (Lamarche et al., 1984; Becker, 1989; Spiecker et al., 1996; Jacoby and D'Arrigo, 1997; Esper et al., 2002; Boisvenue and Running, 2006).

For research and management purposes, a comprehensive overview of long-term changes in forest productivity is needed. This requires assessing their spatial and inter-specific variability among forest resources. Such investigations are highly demanding in terms of growth data collected, and have remained fragmentary to date (Spiecker, 1999). Among available growth data sources, retrospective analyses of dominant height growth are relevant for addressing productivity issues (Martin-Benito et al., 2008; Bontemps et al., 2009), but remain costly. National forest inventories have been initiated to systematically describe the forest resource, but cover restricted periods of time (Spiecker, 1999). Thus, tree ring measurements will likely remain the preferred option for establishing a comprehensive picture of regional and species growth trends.

However, the accuracy of radial growth is questioned for investigating past forest productivity changes. First, the radial growth of individual trees is sensitive to local competition dynamics driven by natural disturbances or silviculture in managed ecosystems (Cook and Kairiukstis, 1990). Since these processes are independent of site fertility conditions, radial growth of trees is not considered a sound indicator of stand productivity potential in forestry in contrast to mean or top heights (Assmann, 1970; Skovsgaard and Vanclay, 2008). Tree sampling in retrospective studies is often restricted to dominant trees, which experience lower competition intensity and belong to a fairly stable population over time (Cook and Kairiukstis, 1990, Becker et al., 1995). Yet, individual shifts in tree competition status may also occur among dominant tree populations (Cherubini et al., 
1998). Second, radial growth is usually sampled at breast height. During severe climatic events, ring width reduction or ring suppression can be more acute at breast height than at higher positions on the stem (Cook and Kairiukstis, 1990; Shapochkin, 1982). Such events modify the relationship between ring size and tree volume increment (Bouriaud et al., 2005).

Despite these shortcomings, dominant tree diameter increments have revealed year-to-year and long-term variations in qualitative accordance with height or volume increments in Pinus sylvestris and Picea abies (Mäkinen, 1998; Mäkinen et al., 2002; Neumann and Röhle, 2002). Similarities in their respective relationships to environmental factors have also been evidenced in several species (Jackson et al. 1976; Ott, 1978; Mäkinen et al., 2002; Neumann and Röhle, 2002). These observations suggest that radial growth can reliably depict the effect of environmental factors on stand productivity. Hence, it may be hypothesized that variations in the competition level do not strongly affect the radial growth of dominant trees, or that management practices do not alter the environmental signal on radial growth as long as they remain fairly stable over longer timescales. An open question is whether the quantitative variations in radial growth over time match those of productivity.

In a previous study, we analysed the changes in forest productivity of even-aged stands of common beech (Fagus sylvatica L.) in north-eastern France (Bontemps et al., 2009). In order to separate the effects of date and ageing on growth and to control site fertility, a sampling strategy based on pairs of young/old neighbour stands located in the same local conditions was designed (Untheim, 1996; Lebourgeois et al., 2000). Dominant height was sampled as a proxy for stand productivity (Eichhorn, 1904; Assmann, 1970) and was reconstructed from stem analyses. The simultaneous separation of the effects of site, developmental stage, and calendar date on dominant height growth rate was performed by a statistical modelling approach, which allowed the chronology of dominant height growth rate to be estimated.

Based on a simultaneous sampling of radial growth of the same dominant trees at $1.30 \mathrm{~m}$, the objectives of this study were twofold: (i) to estimate the chronology in dominant radial growth by 
applying the same statistical methodology and (ii) to compare the radial growth and dominant height growth chronologies in both their qualitative and quantitative dimensions.

\section{MATERIALS}

\section{Sampling design}

The sampling design was described in Bontemps et al. (2009). We focused on pure and even-aged stands of common beech in north-eastern France (Lorraine Plateau and downslopes of the western Vosges hills). In France, even-aged beech stands have been regenerated naturally since the early nineteenth century (Hüffel, 1926), and common beech has not been subject to any breeding programme. Thus, growth differences between stand generations should not be interpreted as a result of genetic progress. In addition, sampling was restricted to State forests to ensure the maximum continuity of forest management and forest structure over time.

We applied the paired-plots method (Untheim, 1996; Lebourgeois et al., 2000) based on pairs of neighbouring stands of different ages and located in the same site conditions to balance site fertility with stand age. Old stands of around standard rotation age were chosen (150-180 years), while young stands were half as old in order to ensure the correct separation of developmental stage and calendar date. Stand pairs were selected after a control of topographic conditions, parent rock and soil, humus layers, and understorey vegetation sampled during summer. To gain a representation of site regional variability, site conditions were varied between pairs.

In total, 14 stand pairs were sampled in 1998. The within-pair distance was $160 \mathrm{~m}$ on average and never exceeded $330 \mathrm{~m}$. Soil analyses to $50 \mathrm{~cm}$ depth were further conducted in each plot to assess the quality of pairing. Measurements were taken for nutritional status $(\mathrm{pH}$, base saturation rate, $\mathrm{C}: \mathrm{N}$ ratio, phosphorus and nutrient concentrations) and water status (maximum soil water capacity). Ellenberg indicators of nutrition and water status (Ellenberg et al., 1992) were predicted from 
vegetation surveys. The control of site conditions was based on a systematic pair-wise comparison of all indicators. Systematic between-generation differences were also investigated using paired ttests. A single difference was found in the Ellenberg basicity indicator, which was higher in the younger stands $(p=0.04)$ but was not reflected in soil analyses $(\mathrm{pH})$. The difference was interpreted as an effect of acidification with stand ageing (Bontemps et al., 2009). The locations and ages of sampled stands are given in Table 1. The mean elevation of stands was $370 \mathrm{~m}$ a.s.l.

\begin{tabular}{|c|c|c|c|c|c|c|c|c|}
\hline \multirow[t]{2}{*}{ Stand pair } & \multirow[t]{2}{*}{ Forest } & \multirow[t]{2}{*}{ Location $^{\text {a }}$} & \multicolumn{3}{|c|}{ Stand age ${ }^{b}$ (years) } & \multicolumn{3}{|c|}{ Dominant radius $(\mathbf{c m})$} \\
\hline & & & Oldest & Youngest & Difference & Oldest & Youngest & Difference $^{c}$ \\
\hline 1 & Haye & $6^{\circ} 05^{\prime} \mathrm{E}, 48^{\circ} 39^{\prime} \mathrm{N}$ & 136 & 72 & 64 & 12.5 & 19.6 & 7.1 \\
\hline 2 & Haye & $6^{\circ} 05^{\prime} \mathrm{E}, 48^{\circ} 40^{\prime} \mathrm{N}$ & 137 & 66 & 71 & 12.9 & 19.7 & 6.8 \\
\hline 3 & Haye & $6^{\circ} 07^{\prime} \mathrm{E}, 48^{\circ} 39^{\prime} \mathrm{N}$ & 143 & 58 & 85 & 15.2 & 15.9 & 0.7 \\
\hline 4 & Sarrebourg & $7^{\circ} 00^{\prime} \mathrm{E}, 48^{\circ} 44^{\prime} \mathrm{N}$ & 109 & 53 & 56 & 12.1 & 16.0 & 3.9 \\
\hline 5 & Hesse & $7^{\circ} 04^{\prime} \mathrm{E}, 48^{\circ} 40^{\prime} \mathrm{N}$ & 157 & 63 & 94 & 5.2 & 17.3 & 12.1 \\
\hline 6 & Lemberg & $7^{\circ} 17^{\prime} \mathrm{E}, 49^{\circ} 00^{\prime} \mathrm{N}$ & 142 & 84 & 58 & $14.7^{*}$ & 23.9 & 9.2 \\
\hline 7 & Mouterhouse & $7^{\circ} 24^{\prime} \mathrm{E}, 49^{\circ} 01^{\prime} \mathrm{N}$ & 132 & 53 & 79 & 12.9 & 14.6 & 1.7 \\
\hline 8 & Goendersberg & $7^{\circ} 26^{\prime} \mathrm{E}, 49^{\circ} 07^{\prime} \mathrm{N}$ & 184 & 47 & 137 & $7.0^{*}$ & 13.7 & 6.7 \\
\hline 9 & Morimond & $5^{\circ} 42^{\prime} \mathrm{E}, 48^{\circ} 03^{\prime} \mathrm{N}$ & 124 & 56 & 68 & 9.7 & 12.6 & 2.9 \\
\hline 10 & La Petite Pierre & $7^{\circ} 18^{\prime} \mathrm{E}, 48^{\circ} 51^{\prime} \mathrm{N}$ & 122 & 39 & 83 & 3.5 & 10.1 & 6.6 \\
\hline 11 & FC Fislis & $7^{\circ} 24^{\prime} \mathrm{E}, 47^{\circ} 31^{\prime} \mathrm{N}$ & 169 & 90 & 79 & 14.1 & 21.6 & 7.5 \\
\hline 12 & Ban d'Uxegney & $6^{\circ} 25^{\prime} \mathrm{E}, 48^{\circ} 10^{\prime} \mathrm{N}$ & 122 & 75 & 47 & 13.8 & 12.4 & -1.4 \\
\hline 13 & Sainte Hélène & $6^{\circ} 39^{\prime} \mathrm{E}, 48^{\circ} 19^{\prime} \mathrm{N}$ & 131 & 65 & 66 & $6.3^{*}$ & 12.0 & 5.7 \\
\hline 14 & Fraize & $6^{\circ} 24^{\prime} \mathrm{E}, 48^{\circ} 21^{\prime} \mathrm{N}$ & 153 & 84 & 69 & 16.3 & 17.9 & 1.6 \\
\hline Mean & & & 140.1 & 64.6 & 75.4 & 11.1 & 16.2 & $5.1 * * *$ \\
\hline $\begin{array}{l}\text { Standard } \\
\text { deviation }\end{array}$ & & & 20.2 & 15 & 21.7 & 4.1 & 4.0 & 3.7 \\
\hline
\end{tabular}

Table 1. Location, age and dominant radius of stands. ${ }^{a}$ mean geographic coordinates of stand pairs (European Datum 50 system), ${ }^{\mathrm{b}}$ stand age at $0.30 \mathrm{~m}$ in $1998,{ }^{\mathrm{c}}$ radius at the age of young stands in 1998. * Growth affected by temporary contraction phases in the early twentieth century amplifying the within-pair difference. 


\section{Growth data}

Dominant trees were defined as the 100 thickest trees at $1.30 \mathrm{~m}$ height per hectare. Accordingly, three dominant trees per stand were sampled in 0.06 hectare circular plots following the Duplat and Tran-Ha (1997) protocol. Stem analyses were performed for the 84 sampled trees and ring measurements were taken on the stem disks sampled at $1.30 \mathrm{~m}$ height. Tree rings were thus systematically measured from the pith and in several radial directions. False rings or partially missing rings were also more easily detected.

On each disk, ring widths were measured to the nearest $1 / 100 \mathrm{~mm}$ along four orthogonal radii distributed from a random primer direction, using a digital positiometer coupled to a binocular microscope. Ring series were cross-dated after identification of pointer years. Individual tree growth series were first computed by taking the quadratic mean of the four ring width series available for each tree.

Consistent with the objective of analysing dominant radial growth, a mean growth series was then computed for each stand. The average growth series provided an estimate of the annual growth rate of dominant radius $\left(R_{0}\right)$, hereafter called dominant radial growth or dominant ring width $\left(R W_{0}\right)$. In total, 2592 annual increments arising from the 28 stands were available. Corresponding radial growth series are plotted against cambial age in Figure 1. 


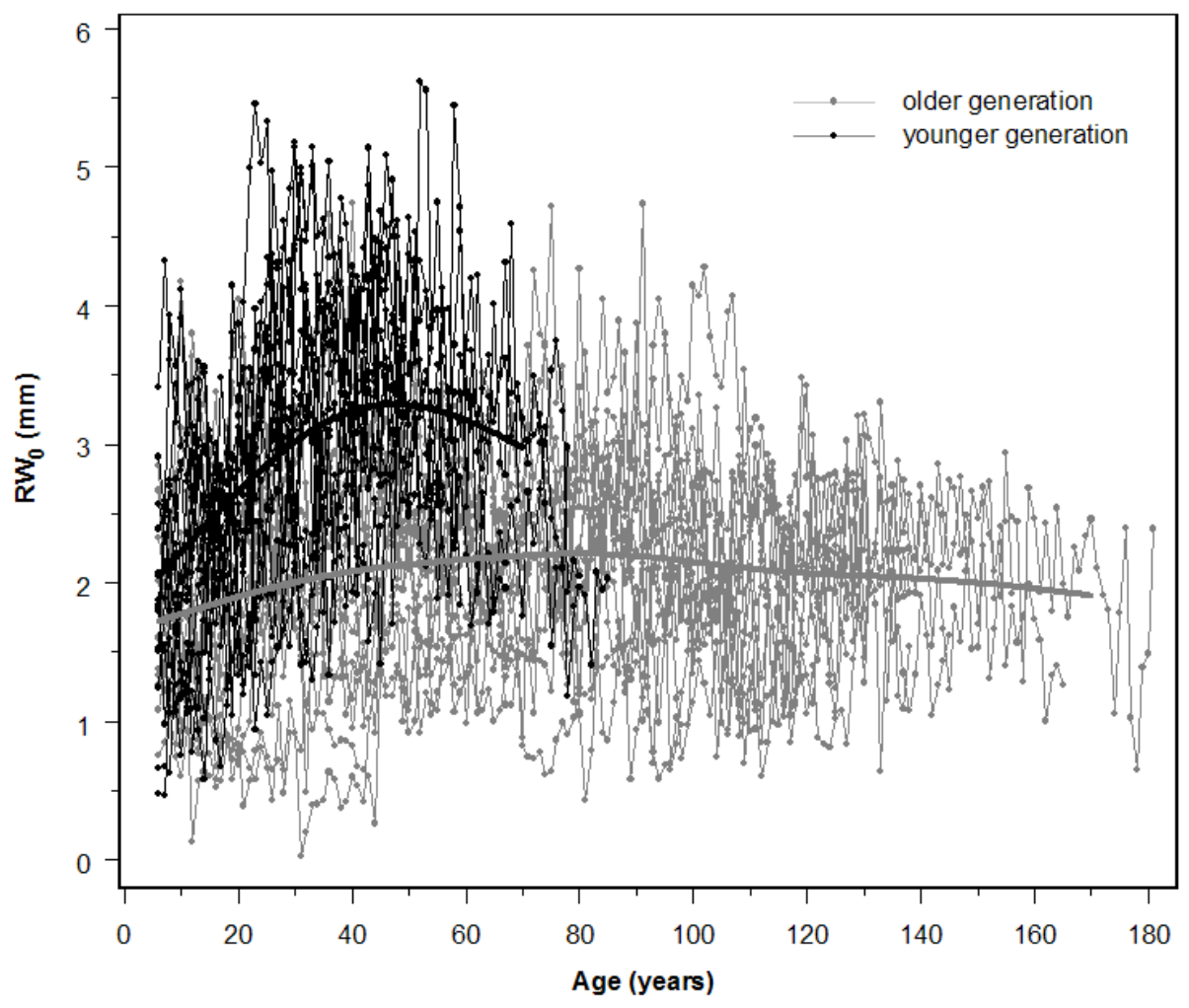

Figure 1. Age patterns of dominant ring width $\left(\mathbf{R} \mathbf{W}_{\mathbf{0}}\right)$. For each generation, dominant ring width series were averaged according to a smoothing spline. Grey thick line: older generation; black thick line: younger generation. 


\section{METHODS}

We adopted the same model formulation and fitting procedure as detailed in Bontemps et al. (2009) for dominant height.

\section{Model structure}

Dominant radial growth rate was written as a multiplicative composition of stand developmental stage, site fertility, and calendar date effects (Garcia, 1989). Because of long-term trends, trees of successive generations differ in size at the same age. Therefore, size was preferred to age as a proxy for developmental stage. Site conditions were represented by a single parameter $\left(S_{b}\right)$ taken at a base calendar date $\left(t_{\mathrm{b}}\right)$. The effect of calendar date was expressed as a function of time elapsed since base date. Past stand density is not documented and cannot be controlled in the model. In continuous time, the aforementioned assumptions lead to the following first order differential equation:

$$
d R_{0} / d t=\mathrm{S}_{\mathrm{b}} f_{1}\left(R_{0}\right) f_{2}\left(t-t_{\mathrm{b}}\right)
$$

where $f_{1}$ is the effect of size, $f_{2}$ is the effect of calendar date, and $f_{2}\left(t_{\mathrm{b}}\right)=1$.

\section{Functional representation}

As seen in Figure 1, developmental stage patterns of radial growth exhibit a maximum followed by a decreasing trend. Therefore, radial growth representation was oriented towards three-parameter first order differential growth equations, generating sigmoid curves in time (Zeide, 1993). Their general form is given by:

$$
d R_{0} / d t=\mathrm{r} f\left(R_{0}, \mathrm{k}, \mathrm{m}\right)
$$

where $\mathrm{r}$ is the intrinsic growth rate (vertical scale parameter, $\mathrm{mm} \cdot \mathrm{yr}^{-1}$ ), $\mathrm{k}$ is the horizontal scale parameter $(\mathrm{mm})$, and $\mathrm{m}$ is the shape parameter.

As radial growth is not asymptotic in the age range sampled (Figure 1), attention was paid to the late growth behaviour of growth equations initially selected. We considered two non-asymptotic 
equations: the Wykoff equation (Wykoff, 1990), often used for describing radial growth (Monserud and Sterba, 1996; Chojnacki, 1997), and a power generalisation of the Michaelis-Menten equation (Briggs and Haldane, 1925; denoted MMg), developed for this study. Their expressions are provided in Eqs. (A.1) and (A.2) of Appendix A. These equations were reparameterised for the vertical and horizontal scale parameters to stand respectively for the maximum growth rate (denoted R) and the radius at which maximum growth rate is observed (denoted K; Eqs. (A.3) and (A.4) in Appendix A). Hence:

$$
d R_{0} / d t=\mathrm{R} f\left(R_{0}, \mathrm{~K}, \mathrm{~m}\right)
$$

The maximum radial growth rate $\mathrm{R}$ was assimilated to the site parameter $\mathrm{S}_{\mathrm{b}}$ of Eq. (1), and $f$ to $f_{1}$. The effect of calendar date $\left(f_{2}\right)$ was successively represented by a linear function (mean trend), a quadratic function (accelerated pattern), and a cubic spline function, intended to identify mediumterm fluctuations and to avoid the excessive fluctuations of traditional polynomials (Burden and Faires, 2001). Their expressions are given in Appendix A (Eqs. (A.5) to (A.7)). Cubic splines were successively tested with 20-, 15-, and 10-year node intervals. The parameters of the calendar date effect were collected in a vector $\theta$.

\section{Statistical methodology}

The sampling design consists of longitudinal data structured according to two nested levels, as defined by stand pairs and stands within pairs (hereafter denoted levels 1 and 2). Accordingly, models were fitted within the frame of hierarchical non-linear mixed-effect models (Lindström and Bates, 1990), allowing to test and estimate the variability in growth equation parameters at these levels (typically, one can postulate a between-pair variation of the site fertility parameter $\mathrm{R}_{\mathrm{b}}$ ).

The instantaneous radial growth rate in Eq. (1) was approximated by the dominant ring width $\left(R W_{0}\right)$. Furthermore, $R W_{0}$ at time $t$ was written dependent on $R_{0}$ at time $t-1$. The assumptions of independence and homoskedasticity of errors were also addressed by introducing a residual variance function as a power of the predicted increments, and a first order autocorrelation process 
(AR1) that proved the most accurate over the majority of growth series (Bontemps, 2002; using the methodology of Monserud, 1986. Some series also agreed well with an AR2 structure). The statistical model was written as:

$$
R W_{0}(t)=\mathrm{S}_{\mathrm{b}} f_{1}\left(R_{0}(t-1), \mathrm{K}, \mathrm{m}\right) f_{2}\left(t-t_{\mathrm{b}}, \theta\right)+\varepsilon_{t}
$$

with:

$$
\begin{aligned}
& \mathcal{E}_{t}=\phi \varepsilon_{t-1}+e_{t}, e_{t} \sim \mathrm{N}\left(0, \mathrm{~V}\left(e_{t}\right)\right), \mathrm{V}\left(e_{t}\right)=\sigma^{2} R \hat{W}_{0}(t)^{2 \lambda} \\
& \mathrm{S}_{\mathrm{b}}=\mathrm{S}_{\mathrm{b} 0}+\mathrm{S}_{\mathrm{b}, 1}+\mathrm{S}_{\mathrm{b}, 2}, \mathrm{~S}_{\mathrm{b}, \mathrm{i}} \sim \mathrm{N}\left(0, \sigma_{\mathrm{Sb}, \mathrm{i}}\right), \mathrm{i}=1,2 \\
& \mathrm{~K}=\mathrm{K}_{0}+\mathrm{K}_{1}+\mathrm{K}_{2}, \mathrm{~K}_{\mathrm{i}} \sim \mathrm{N}\left(0, \sigma_{\mathrm{K}, \mathrm{i}}\right), \mathrm{i}=1,2 \\
& \rho_{\mathrm{i}}=\operatorname{cor}\left(\mathrm{S}_{\mathrm{b}, \mathrm{i}}, \mathrm{K}_{\mathrm{i}}\right), \mathrm{i}=1,2
\end{aligned}
$$

where $\phi$ is the first order autocorrelation, $\lambda$ is the error function power term, $S_{b, i}$ and $K_{i}$ are putative random components of $S_{\mathrm{b}}$ and $\mathrm{K}$ at level $\mathrm{i}$, and $\sigma_{\mathrm{Sb}, \mathrm{i}}$ and $\sigma_{\mathrm{K}, \mathrm{i}}$ are their standard deviations. $\mathrm{S}_{\mathrm{b} 0}, \mathrm{~K}_{0}$, $\mathrm{m}, \theta, \sigma_{\mathrm{Sb}, \mathrm{i}}, \sigma_{\mathrm{K}, \mathrm{i}}, \phi, \sigma$, and $\lambda$ are the fixed parameters. Parameter vector $\theta$ in $f_{2}$ (Eq. (4)) was held fixed because the aim was to estimate the mean growth trend over the sample.

Models were fitted using the maximum likelihood criterion of the nlme procedure in S-PLUS software (Pinheiro and Bates, 2000) and compared according to the Akaike information criterion (AIC). Nested models were further compared according to the likelihood ratio test (LRT) chisquared statistics.

\section{Modelling strategy}

The model was built in four steps. Step 1: the accuracy of the two selected growth equations was compared with a fit restricted to the long growth series from the older generation. Parameters $S_{b}$ and $\mathrm{K}$ were allowed to vary between stands. The shape parameter $\mathrm{m}$ was held constant. Step 2: the most accurate equation from step 1 was retained and fitted to the whole dataset. The model of errors was introduced. A simple linear effect of date was then tested. Step 3: the structure of variation of parameters $S_{\mathrm{b}}$ and $\mathrm{K}$ at levels 1 and 2 was carefully investigated. Step 4: the effects of calendar date were successively tested and refined until the final model was obtained. 


\section{RESULTS}

\section{Data exploration}

Values of the stand dominant radius are reported in Table 1. At a mean age of 65 years, young stands showed an average dominant radius of $16.2 \mathrm{~cm}$, corresponding to a very significant increase of $5.1 \mathrm{~cm}$ when compared with older stands $\left(p=1.710^{-4}\right)$. A negative difference was observed in only one of the 14 paired stands (pair 12). For some stand pairs identified in Table 1, the difference was amplified by sudden growth suppression phases observed in the older stands of pairs 6,8 , and 13. In accordance with the systematic difference found, radial growth patterns (Figure 1) depicted a higher average growth level for the younger generation over the whole cambial age range. A clear trend towards an earlier occurrence of maximum growth rate among the younger generation was also apparent.

Stand trajectories in dominant height against dominant radius are compared between generations in Figure 2 and showed no between-generation average difference. Since a positive shift in dominant height growth was evidenced (Bontemps et al., 2009), a shift of similar intensity was thus inferred for dominant radial growth.

The suppression phases identified visually in pairs 6,8 , and 13 occurred in the early 20th twentieth century and it is unlikely they were of environmental origin. As they presented a risk of overestimating the historical evolution of radial growth, the corresponding ring widths were eliminated from growth series (213 increments), leading to a final 2379 increment dataset. 


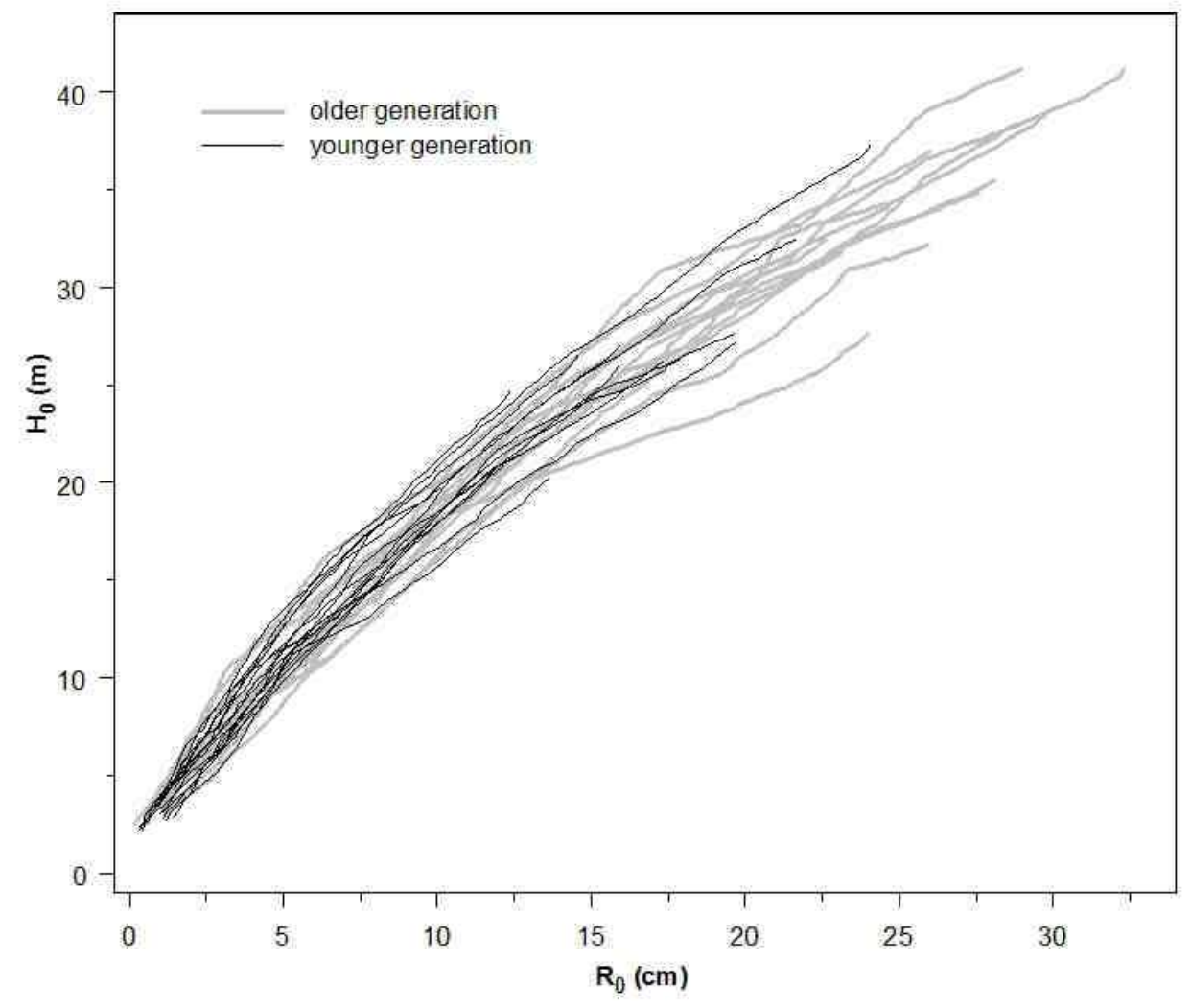

Figure 2. Stand trajectories in the dominant radius-dominant height phase plane. Each trajectory was drawn from mean height and radius time series (see text) over the three dominant trees sampled in each stand. 


\section{Chronology of radial growth rate}

The main modelling steps are reported in Appendix B and summarised in Table 2. The mean chronology is plotted in Figure 3a, together with its 95\% bilateral confidence interval (Bontemps et al., 2009). Annual increments were divided by the estimates of site and developmental stage effects (see Eq. (4)) and superimposed on the mean trend. A considerable variability in increment level around the mean chronology was observed. A progressive increase in the radial growth rate was displayed, which first culminated around $+28 \%$ in the 1920 s and reached a maximum of $+47 \%$ in the mid 1980s. The progression was disrupted by major pluri-annual negative growth events occurring in the 1940s and 1990s and by two events identified in 1964 and 1976 but short enough to remain undetected using the 15-year cubic spline function (a slowing was detected in the 1970s). The 1950-1990 period was very favourable to radial growth.

The chronology showing the recent divergence between generations is plotted in Figure $\mathbf{3 b}$. Whereas the radial increment level of younger stands culminated at around $+50 \%$ and remained around $+40 \%$ during the 1990 s, the maximum was around $+40 \%$ for the older stands before a severe decline. Standardised increments of the older stands also tended to be lower during the 1970s and 1990s. 


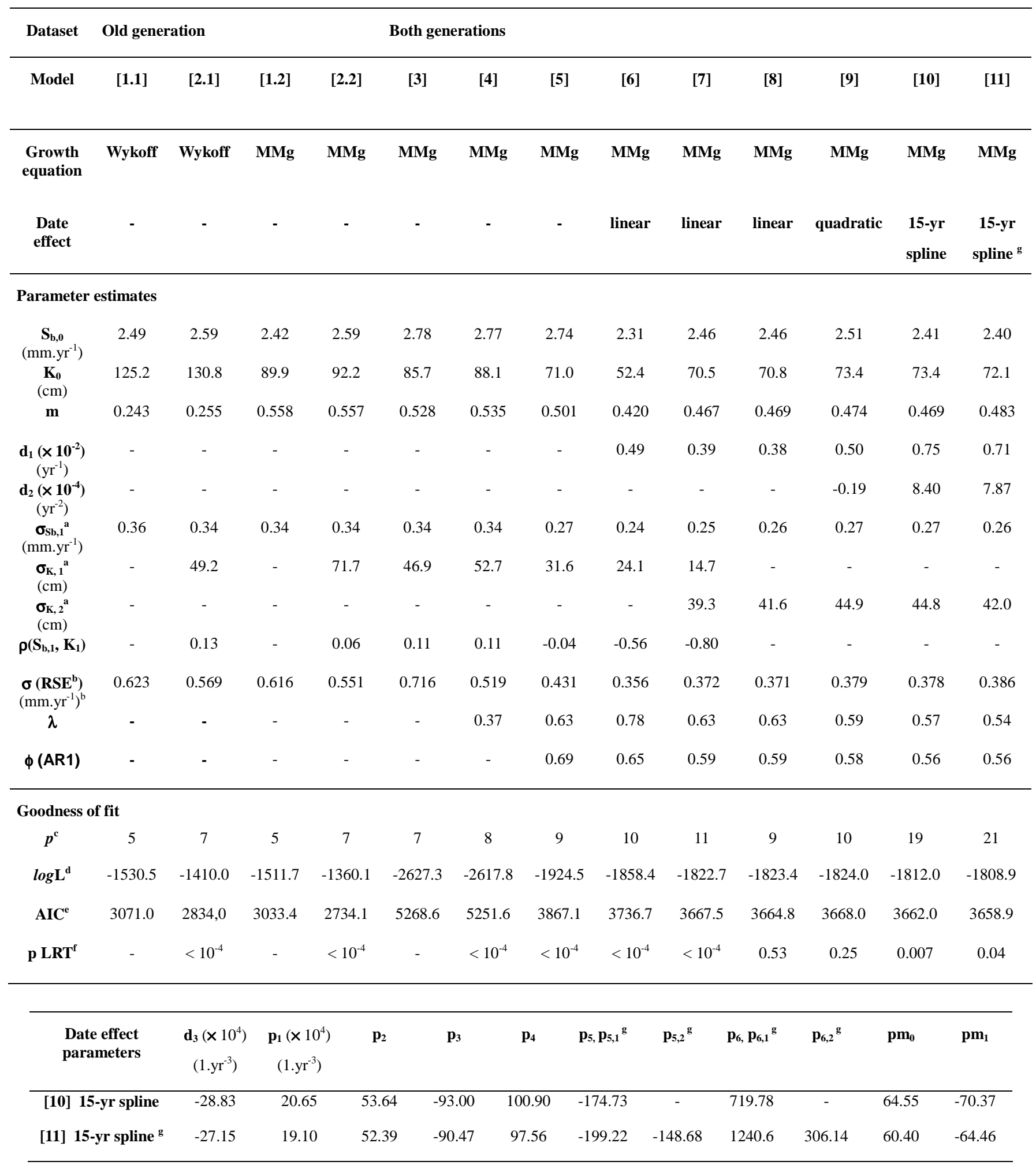

Table 2. Characteristics and parameter estimates of main statistical models. ${ }^{\text {indexes denote }}$ random variation level for standard deviation estimates, ${ }^{b}$ in absence of variance function, ${ }^{c}$ number of model parameters, ${ }^{\mathrm{d}} \log$-likelihood, ${ }^{\mathrm{e}}$ Akaike information criterion, ${ }^{\mathrm{f}} p$-value associated to likelihood ratio tests (LRT) between successive nested models presented, ${ }^{\mathrm{g}}$ spline function differentiated between stand generations from 1975 (indexes 1 and 2 on parameters $\mathrm{p}_{5}$ and $\mathrm{p}_{6}$ refer to stand generations). 


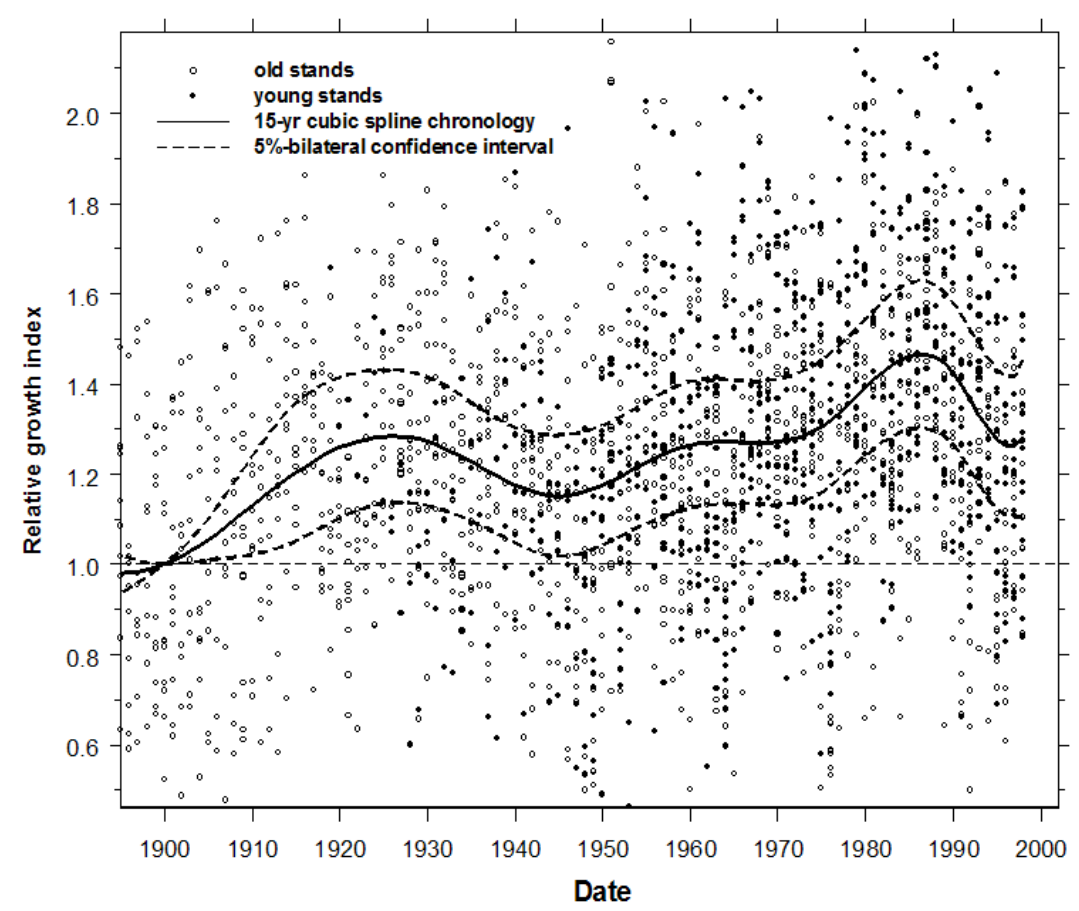

a.

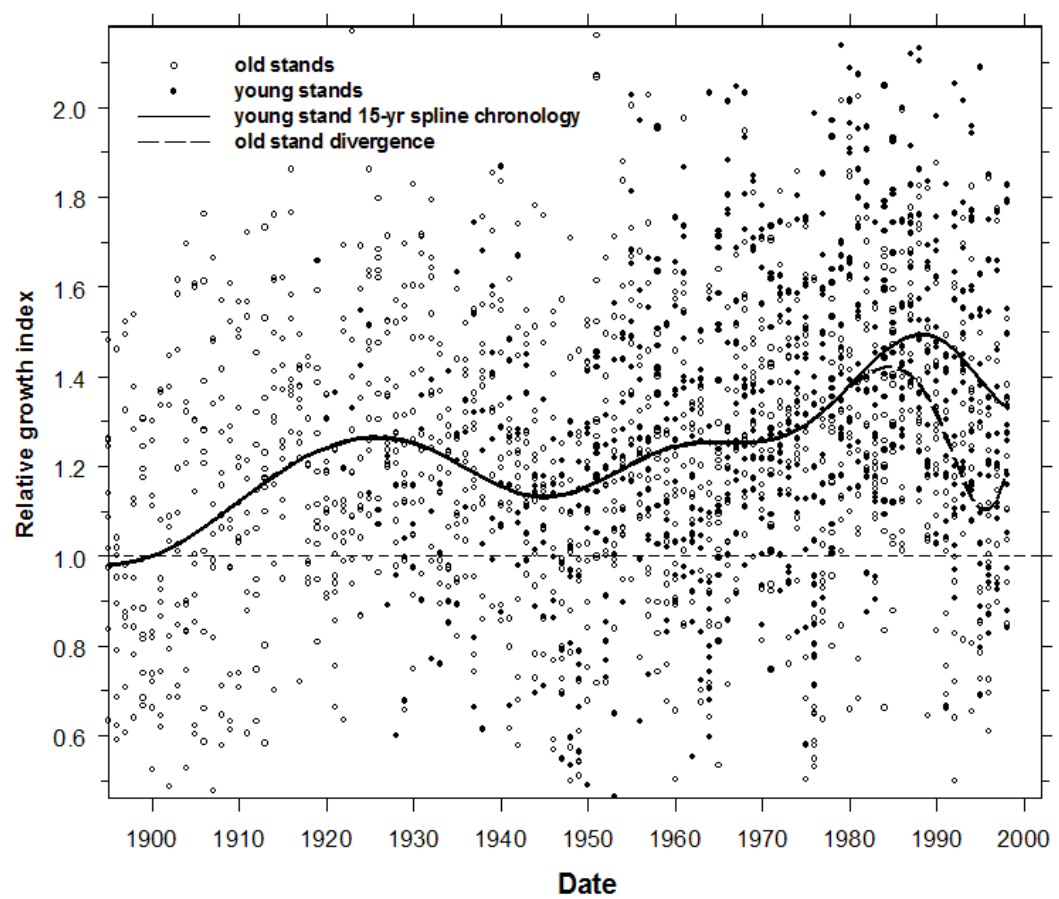

b.

Figure 3. Historical evolution of dominant radial growth rate. a: mean chronology; b: differentiation between stand generations from 1975. Rings widths were filtered out from the effects of site and developmental stage. 


\section{Comparison with the chronology of dominant height growth rate}

The chronologies of dominant height growth (Bontemps et al., 2009) and dominant radial growth are superimposed in Figure 4. Both agreed on: (i) a secular increase in growth rate; (ii) the occurrence of major growth crises in the 1940s and 1990s; (iii) a steady increase in growth rate between the 1950s and 1980s; and (iv) a comparable magnitude, with maximum increases of $60 \%$ and $50 \%$ reached in the 1980 s, for dominant height and radial growth respectively. When averaged over the century, the increases in growth rate were also similar $(+27 \% /+25 \%)$.

However the dominant height chronology depicted a clear acceleration pattern from the midtwentieth century, whereas the radial growth increase followed a more linear trend. In particular, the radial growth increase in the early part of the century was more acute than that of dominant height growth, reaching $+28 \%$ in the 1920 s and not falling below $+20 \%$ mid century. This contrasted with a $+20 \%$ level for dominant height, which was affected by a pluri-annual growth decline. Also, the maximum level of dominant radial growth reached in the 1980 s was $10 \%$ below that for dominant height. A growth inflection was also visible in the 1970s in radial growth but not in height growth. Finally, a recent divergence between generations was evidenced in radial growth (Figure 3b) but not in dominant height, although the level of height increments also tended to be lower among older stands in the 1990s (Bontemps et al., 2009). 


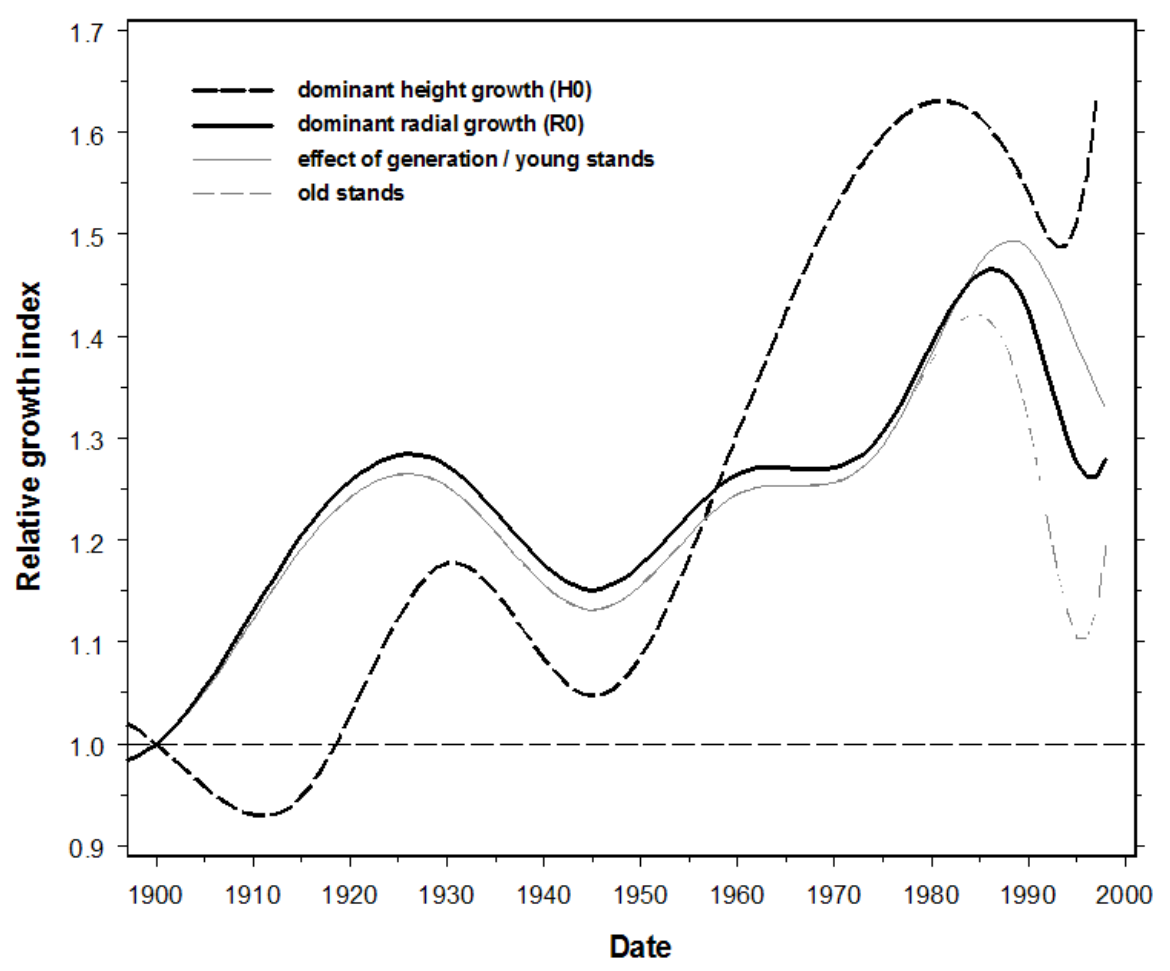

Figure 4. Comparison of the historical evolutions of dominant height and dominant radial growth rates over the twentieth century. The dominant height chronology has been estimated using a similar statistical modelling approach (see Bontemps et al., 2009). Both chronologies of Figure 3 are represented. 


\section{DISCUSSION}

\section{Possible effects of historical management of beech stands}

Because the objective of this study was to understand the potential of radial growth for assessing long-term changes in forest productivity, the sampling was oriented towards reducing the impact of forest management as much as possible. However, past density conditions are not known for the sample, and density variations in time and across stand pairs can show up in data and in the model effects. These two aspects are thus discussed.

\section{Indications for forest management provided by the literature}

First, natural regeneration of common beech has long been common practice in France. Beech is unable to grow from stumps (Mormiche, 1981; Boppe, 1889): present stands thus cannot originate from the maturing of coppices during their conversion in the nineteenth century (Hüffel, 1926). There has also been no genetic breeding programme running, and the scarce existing plantations originate from seeds collected in natural stands. Second, the sampling was restricted to State forests to ensure management continuity over time and to avoid management contingencies linked to ownership changes. Last, beech stands have been historically managed at high density, and recommendations for management intensification are recent (Polge, 1981; Duplat and RomanAmat, 1996).

Indications for forest management provided by data analysis

In some cases, growth data analysis suggests possible silviculture-related signals. First, several decennial suppression phases have been easily identified in the growth series of three old stands and refer to the late nineteenth century or early twentieth century. A silvicultural origin is almost certain because these phases are transient and affect the 3 sampled trees in these stands. They may also correspond to local crown damages following thinnings. These parts of curves were removed from the dataset and did not affect the estimated radial growth chronologies. Second, the significant 
recent divergence in growth evolution between generations (Figure 3b, Table 2) may arise from management practices. Whereas management options are restricted for stands in the age range of the older stands sampled (not far from harvest diameter), the younger stands may have been the preferential target of recent intensification (Duplat and Roman-Amat, 1996) and may hence have expressed a higher growth. However, the age-related sensitivity of growth to climatic events has also been evidenced (Carrer and Urbinati, 2004; Esper et al., 2008). Consistent with that hypothesis, the divergence is observed at a recent period of unusual global warming (Moisselin et al., 2002) and corresponds to a growth decline (see also dominant height, Figure 3). Recent drought-driven reduction in beech growth has been reported in Jump et al. (2006) and Piovesan et al. (2008) in Mediterranean and mountain contexts. Jump et al. also suggested that older trees are more susceptible to growth declines. Third, the systematic between-generation difference in the radius of maximum growth rate $(\mathrm{K})$ is challenging (Figure 1, Table 2). This shift may be attributable to either environment- or silviculture-related changes. An environment-related hypothesis is that the maximum growth rate usually occurs at earlier developmental stages in better fertility conditions (Assmann, 1970; Beck, 1971; Ryan et al., 1997). This may also apply over time when environmental conditions are improved. The hypothesis is however challenged by the absence of correlation between the position and level of maximum growth rate ( $\mathrm{K}$ and $\left.\mathrm{S}_{\mathrm{b}}\right)$ in the fit restricted to the 14 older stands (fits [2.1] and [2.2] in Table 2). A management-related hypothesis is that the optimum size is also governed by the establishment of competition in stands (Smith and Long, 2001). In our sample, some older stands may have originated from natural regeneration after oak coppices with beech standards (Hüffel, 1926). A possibly low regeneration density may have resulted in delaying the occurrence of maximum growth rate. Depending on the origin of the observed difference, the consequences for the long-term trend estimate differ. If we consider the environment-related hypothesis, the impact of environmental change on the shape of the growth pattern is overlooked by assessing long-term changes in maximum growth rate only. If we consider the management-related hypothesis, lower historical stand densities would have led to higher radial 
growth in older stands and therefore to underestimation of the true magnitude of growth change.

In summary, historical changes in silviculture appear to be limited for our sample. Indications for possible management effects on growth are accounted for in the model and are also challenged by adverse hypotheses.

\section{Modelling of dominant radial growth}

The use of asymptotic growth equations was initially associated with a potential risk of underestimating intrinsic growth and thus of overestimating the magnitude of the historical change. For this reason, non-asymptotic growth equations were preferred. Earlier work (Bontemps, 2002; not reported here) was also carried out with the asymptotic Korf growth equation (Zeide, 1993). A systematically lower fitting accuracy and unrealistic estimates for the asymptote were obtained (asymptotic radius over $17 \mathrm{~m}$ ). This suggested a low interpretability of such equations.

The non-asymptotic Wykoff growth equation (Wykoff, 1990) was selected for its repeated use in radial growth modelling. However, the exponential size-related decline in the autonomous differential equation form of the Wykoff model (Eq. (A.1)) was considered to be too fast. Thus, we proposed an original equation (Eq. (A.2)) with an inverse-of-size decline term. This proved more accurate than the Wykoff equation. Non-asymptotic equations have rarely been proposed for growth modelling (Duplat and Tran-Ha, 1997; Cieszewski, 2003). Because some growth processes are fundamentally not asymptotic (radial growth) or age ranges covered in usual data do not provide reliable estimates of the asymptote parameter, such equations may deserve better attention.

\section{Comparison of dominant height and dominant radial growth chronologies}

The chronologies of dominant height and radial growth reveal strong similarities in both their magnitude and medium-term fluctuations (Figure 4). The average increase in dominant radial growth $(+25 \%$, SD $6.7 \%)$ reported for the last century is similar to that of dominant height. The height to diameter ratio of dominant trees is thus not affected by long-term growth trends. The 
multiplicative structure of the models and the use of size as a proxy for developmental stage (Eq. (1)) also imply a dynamical interpretation of this estimate as a time contraction factor of $20 \%$ for reaching a given dominant height or diameter (Bontemps et al., 2009). Hence the following management-oriented interpretations are permitted: (i) regarding dominant height, an average of $20 \%$ less time is required for reaching the same dominant height and thus total production level, and it is accurately inferred from dominant radial growth, (ii) because rotations are most often conditioned by harvest diameter at a stage where dominant trees prevail as a population, the historical change in dominant radial growth can also be interpreted as a contraction of rotation time. However, radial and height chronologies do not always match in their detailed variations. This can be accounted for by the difference in temporal resolution of radial and height increments, and by the difference in intra-annual timing of primary and secondary growth. First, radial growth was measured annually and extreme increments appear as isolated over the calendar year (Figure 3). Because the cubic spline function is intended to reflect medium-term fluctuations, it smoothes growth fluctuations and reduces their amplitude. By contrast, height increments are pluri-annual (mean duration $7.2 \mathrm{yr}$, SD $3.9 \mathrm{yr}$, Bontemps et al., 2009) and were found much closer to the spline function variations. However, this does not account for differences such as the early century decrease in dominant height growth and its absence of inflection in the 1970s. The latter period corresponds to several dry years during which growth was strongly affected (Lebourgeois et al., 2005). Since height growth usually stops earlier than radial growth in the vegetation period, it may be less affected by such climatic events (Mäkinen et al., 2002). The sensitivity of radial growth to drought is moreover strengthened when it is sampled at breast height rather than at higher positions along the stem (Shapochkin, 1982; Bouriaud et al., 2005). A compared modelling approach of height and radial growth-climate relationships (Mäkinen et al., 2002) would permit to highlight the role of climate in these differences.

\section{Radial growth of dominant trees as a proxy for productivity?}


Since dominant height is generally insensitive to density (Assman, 1970; Pienaar and Shiver, 1984; Lanner, 1985) and shows a strong link with total stand production (Eichhorn, 1904; Assmann, 1970), it has long been considered the primary proxy for the productivity of even-aged stands in forestry (Skovsgaard and Vanclay, 2008). On the contrary, radial growth is reputed to be sensitive to the level of competition and has been set aside as a basis for defining productivity proxies. However, the sparse studies available indicate that height and diameter increments correlate in their annual and medium-term historical fluctuations (Mäkinen, 1998; Neumann and Rohle, 2002), while similarities in their climatic determinism have been pointed out (Jackson et al., 1976; Ott, 1978; Mäkinen et al., 2002). Consistently, the radial growth of dominant trees has been reported to be unaffected (Pardé, 1981) or much less affected than other tree statuses (McKenzie and Hawke, 1999; Peltola et al., 2007) by contrasted thinning intensities or planting densities.

To assess the impact of tree status and local dynamics on radial growth of dominant trees, we also fitted both radial and height models to individual tree growth data. The estimates of the tree to site relative variation of site parameter (introducing a "tree" - or level 3 - random effect on site parameter in models) were $27.2 \% / 2.9 \%$, for radial and height growth respectively. This suggested that site remained predominant in the variation of radial growth, despite individual tree variation was an order of magnitude higher than on dominant height. We also found a fair correlation of +0.56 ( $p=0.04, \mathrm{n}=14$ pairs) between the site parameter estimates from the dominant radial growth $\left(S_{b}\right)$ and height growth models (parameter $R_{b}$ in Bontemps et al. 2009).

Whether an approach based on the radial growth of dominant trees can meet generality for the diagnosis of productivity changes may thus be answered in two steps. First, because the estimate of growth change over time is relative to both a reference period and competitive state of the production system, the diagnosis may remain accurate as long as a condition of management stationarity is achieved in the forest resource considered. Here, a useful test may be provided by applying a similar diagnosis to a species experiencing intensive management. Second, depending on the magnitude of the radial growth response of dominant trees to thinning and its variation across 
species, the condition of management stationarity may also prove optional. Further research is thus needed on that issue.

\section{CONCLUSIONS}

An increase of 50\% (SD: 6.7\%) in the radial growth rate of dominant trees is reported for even-aged stands of common beech in north-eastern France over the twentieth century. Several decline events affecting radial growth are also observed. Dominant height and radial growth chronologies present important similarities including an increase in growth rate, a synchronicity of decline events in the 1940s and 1990s, and a similar order of magnitude. One important outcome of the study is thus that fair conclusions regarding mean trends in productivity and potential rotation times can be inferred from dominant radial growth. Another consequence is the stationarity of the mean height/diameter ratio of dominant trees. Yet, no conclusion can be drawn regarding possible stem taper variations over time given available data.

Historical shifts in silviculture are limited for common beech in north-eastern France. Still, dominant trees are usually less affected by thinning events and we hypothesise that dominant radial growth may prove a better proxy for productivity and the extension of productivity change diagnoses than usually expected. Further analyses on that issue are required.

\section{ACKNOWLEDGEMENTS}

We gratefully thank the French Ministry for Agriculture and Fisheries (MAP) as well as the French Forest Service (ONF) for providing funding and support to the present study. The first author was also funded by a PhD grant from the MAP. We also wish to thank: C. Richter, J.-L. Dupouey, B. Renaux for their contribution to sample elaboration as well as in situ ecological appraisal, D. Rittié for conducting tree-ring measurements, and J.-M. Leban for his helpful comments on the manuscript. 


\section{Appendix A. Functional expressions for the model components}

\section{Differential expressions of growth equations tested}

Wykoff equation: $\quad d R_{0} / d t=\mathrm{r} R_{0}{ }^{\mathrm{m}} \exp \left(-R_{0}{ }^{2} / \mathrm{k}^{2}\right) \quad$ with $\mathrm{m}<1$ and $\mathrm{k}>0$

MMg equation: $\quad d R_{0} / d t=\mathrm{r} R_{0}{ }^{\mathrm{m}} /\left(R_{0}+\mathrm{k}\right) \quad$ with $\mathrm{m}<1$ and $\mathrm{k}>0$

where $\mathrm{r}$ is the intrinsic growth rate $\left(\mathrm{mm} \cdot \mathrm{yr}^{-1}\right), \mathrm{k}$ is the horizontal scale parameter $(\mathrm{mm})$, and $\mathrm{m}$ is the shape parameter. In the case of Eq. (A.2), note that the generalisation of the Michaelis-Menten equation lies in the power of parameter $\mathrm{m}$.

\section{Reparameterisations of growth equations}

Eqs. (A.1) and (A.2) were reparameterised with R as the maximum growth rate instead of r, and K as the radius at which $\mathrm{R}$ is reached:

Wykoff equation: $\quad d R_{0} / d t=\mathrm{R}\left(R_{0} / \mathrm{K}\right)^{\mathrm{m}} \exp \left(\mathrm{m} / 2\left(1-R_{0}{ }^{2} / \mathrm{K}^{2}\right)\right) \quad$ with $\mathrm{m}<1$

MMg equation: $\quad d R_{0} / d t=\mathrm{R}\left(R_{0} / \mathrm{K}\right)^{\mathrm{m}} /\left(1-\mathrm{m}+\mathrm{m}\left(R_{0} / \mathrm{K}\right)\right) \quad$ with $\mathrm{m}<1$

\section{Functions tested for calendar date effect}

Linear: $\quad f_{2}(t)=1+\mathrm{d}_{1}\left(t-t_{\mathrm{b}}\right)$

Quadratic: $\quad f_{2}(t)=1+\mathrm{d}_{1}\left(t-t_{\mathrm{b}}\right)+\mathrm{d}_{2}\left(t-t_{\mathrm{b}}\right)^{2}$

Cubic spline: these are continuous piecewise polynomials of degree three, defined on successive intervals of equal range:

$$
f_{2}(t)=1+\mathrm{d}_{1} u+\mathrm{d}_{2} u^{2}+d_{3} u^{3}+\sum_{\mathrm{k}=1}^{k_{1}} \mathrm{p}_{\mathrm{k}}(\max (u-n \mathrm{k}, 0))^{3}+\sum_{k=0}^{k_{2}} \mathrm{pm}_{\mathrm{k}}(\min (u+n \mathrm{k}, 0))^{3}
$$

where $u=t-t_{\mathrm{b}}, \mathrm{d}_{1}, \mathrm{~d}_{2}, \mathrm{~d}_{3}, \mathrm{p}_{\mathrm{k}}$, and $\mathrm{pm}_{\mathrm{k}}$ series are spline parameters to be estimated, collected in a vector $\theta,[0, n]$ is the base internode of spline, and $n, k_{1}$, and $k_{2}$ externally specify the width and 
number of spline intervals necessary to describe the entire period range covered. For instance, with a 20-year node interval, nodes are located at 1880,1900,1920, .., up to 1980. 


\section{Appendix B. Elaboration of the statistical model}

The main model fits are summarised in Table 2.

\section{Selection of a growth equation (step 1)}

Growth equations were fitted to growth series of older stands, first with a level 1 variation of the maximum growth rate $\left(S_{b}\right)$ alone (models [1.1] and [1.2]). The Wykoff equation proved less accurate than the MMg (see AIC, Table 2). The mean maximum growth rate was estimated at 2.5 $\mathrm{mm} /$ year, with a noticeable between-pair variation (coefficient of variation around $15 \%$ ). Because the growth curves of older stands were depicted quite flat on Figure 1, the invariance of K was difficult to decide. A level 1 variation of parameter $\mathrm{K}$ was thus tested ([2.1] and [2.2]) and shown to be significant. In each case, correlations between $S_{b}$ and $K$ were weak, suggesting no relationship between these two parameters. The better fitting accuracy of the MMg equation was confirmed. The equation was thus selected for the next modelling steps.

\section{Fit to the whole dataset and model of errors (Step 2)}

Consistent with Figure 1, an increase in the estimate of $S_{b}$ and a decline in that of $\mathrm{K}$ were observed when the former model was fitted to the whole dataset ([3]). The power function for residual variance was introduced and led to a significantly better fit $\left(p<10^{-4},[4]\right)$. The power parameter estimate was 0.37 . The model of errors was completed by an AR1 structure ([5]) that proved very significant. The autocorrelation estimate was +0.67 . A very significant $\left(p<10^{-4}\right) 49 \%$ increase in growth rate over 100 years was found when a linear effect of calendar date was introduced into the model ([6]). The level 1 correlation between $S_{b}$ and $K$ increased to -0.56 .

\section{Structure of random parameters (Step 3)}

Since a difference in the mean position of maximum growth rate between generations was 
highlighted, a level 2 variation of K was tested ([7]) and resulted in a significantly better model ( $p<$ $10^{-4}$ ). The average value of $\mathrm{K}$ was estimated as $5.8 \mathrm{~cm}$ among the younger generation against 8.1 $\mathrm{cm}$ in the older one. Finally, the fit was not significantly worse when the level 1 variation of $\mathrm{K}$ was removed ( $p=0.53,[8])$. Other parameter estimates remained stable (Table 2).

\section{Effect of calendar date (Step 4)}

The quadratic effect of calendar date did not provide a better fit [9]. The 20-year node interval cubic spline significantly improved the fit accuracy $(\mathrm{p}=0.01,-6$ AIC units, not presented), as did the 15year equivalent $(p=0.007,[10])$. Further reductions in spline node interval did not lead to any better fit and the 15-year node interval was retained in the final model. Residuals versus calendar date denoted a positive divergence of the younger stands from the older ones in the recent decades. Consequently, between-generation splits in spline parameters at node 1990 alone $\left(\mathrm{p}_{6}\right)$ and then at both nodes 1975 and $1990\left(\mathrm{p}_{5}\right.$ and $\mathrm{p}_{6}$ ) were tested. The second parameterisation (separation of calendar chronology from 1975) was significant $(\mathrm{p}=0.04,[11])$. 


\section{References}

Assmann, E., 1970. The Principles of Forest Yield Study. Pergamon Press, Oxford, p. 45, pp. 160163.

Beck, D.E., 1971. Height-growth patterns and site index of white pine in the Southern Appalachians. For. Sci. 17, 252-260.

Becker, M., 1989. The role of climate on present and past vitality of silver fir forests in the Vosges mountains of northeastern France. Can. J. For. Res. 19, 1110-1117.

Becker, M., Bert, G.D., Bouchon, J., Dupouey, J.-L., Picard, J.-F., Ulrich, E., 1995. Long-term changes in forest productivity in northeastern France: the dendroecological approach, in: Landmann, G., Bonneau, M. (Eds.), Forest Decline and Atmospheric Deposition Effects in the French Mountains. Springer, Berlin, Heidelberg, New-York, pp. 143-156.

Boisvenue, C., Running, S.W., 2006. Impacts of climate change on natural forest productivity evidence since the middle of the 20th century. Glob. Change Biol. 12, 862-882.

Bontemps, J.-D., 2002. Analysis of radial growth in even-aged common beech stands of northeastern France. Growth rate evolution during the 20th century (in French). Master's Thesis, ENGREF, Nancy, France, 23 p.

Bontemps, J.-D., Hervé J.-C., Dhôte J.-F., 2009. Long-term changes in forest productivity: a consistent assessment in even-aged stands. For. Sci., in press.

Boppe, L., 1889. Sylviculture bill [In French], Berger-Levrault, Paris-Nancy, France.

Bouriaud, O., Breda, N., Dupouey, J.L., Granier, A., 2005. Is ring width a reliable proxy for stembiomass increment? A case study in European beech. Can. J. For. Res. 35, 2920-2933.

Briggs, G.E., Haldane, J.B.S., 1925. A note on the kinetics of enzyme action. Biochem. J. 19, 338339.

Burden, R.L., Faires, J.D., 2001. Numerical Analysis, seventh ed. Brooks/Cole, USA.

Carrer, M., Urbinati, C., 2004. Age-dependent tree-ring growth responses to climate in Larix decidua and Pinus cembra. Ecology 85, 730-740. 
Cherubini, P., Dobbertin, M., Innes, J.L., 1998. Potential sampling bias in long-term forest growth trends reconstructed from tree rings: a case study from the Italian Alps. For. Ecol. Manag. $109,103-118$.

Chojnacky, D.C., 1997. Modeling diameter growth for pinyon and juniper trees in dryland forests. For. Ecol. Manag. 93, 21-31.

Cieszewski, C.J., 2003. Developing a well-behaved dynamic site equation using a modified Hossfeld IV function $\mathrm{Y} 3=\mathrm{ax}^{\mathrm{m}} /\left(\mathrm{c}+\mathrm{x}^{\mathrm{m}-1}\right)$, a simplified mixed-model and scant subalpine fir data. For. Sci. 49, 539-554.

Cook, E.R., Kairiukstis, L.A. (Eds.), 1990. Methods of dendrochronology. Kluwer Academic Publishers, Dordrecht Boston London, pp. 26-28, 98-102, 104-123.

Duplat, P., Roman-Amat, B., 1996. Silviculture of common beech (in French). Bull. Tech. ONF 31, $29-33$.

Duplat, P., Tran-Ha, M., 1997. Modelling of dominant height growth of sessile oak (Quercus petraea Liebl) in France. Regional variability and effect of the recent period (1959-1993) (in French). Ann. For. Sci. 54, 611-634.

Eichhorn, F., 1904. Relationship between stand height and stand growing stock (in German). Allgemeine Forst- und Jagd-Zeitung 80, 45-49.

Ellenberg, H., Weber, H.E., Düll, R., Wirth, V., Werner, W., Paulissen, D., 1992. Floristic indices of plants in mid-Europe. Scripta Geobotanica 18, 1-248.

Esper, J., Cook, E.R., Schweingruber, F.H., 2002. Low-frequency signals in long tree-ring chronologies for reconstructing past temperature variability. Science 295, 2250-2252.

Esper, J., Niederer, R., Bebi, P., Frank, D., 2008. Climate signal age effects - evidence from young and old trees in the Swiss Engadin. For. Ecol. Manag. 255, 3783-3789.

Garcia, O., 1989. Forest modelling - new developments, in: Nagumo, H., Konohira, Y. (Eds.), Japan and New Zealand Symposium on Forestry Management Planning. Japan Association for Forestry Statistics, pp. 152-158. 
Hüffel, G., 1926. Methods of Forest Planning in France (in French). Berger-Levrault, Nancy Paris Strasbourg.

Jackson, D.S., Gifford, H.H., Chittenden, J., 1976. Environmental variables influencing the increment of Pinus radiata: (2) Effects of seasonal drought on height and diameter increment. N.Z. J. For. Sci.5, 265-286.

Jacoby, G.C., D'Arrigo, R.D., 1997. Tree rings, carbon dioxide, and climatic change. Proc. Natl. Acad. Sci. 94, 8350-8353.

Jump, A.S., Hunt, J.M., Penuelas, J., 2006. Rapid climate change-related growth decline at the southern range edge of Fagus sylvatica. Glob. Change Biol. 12, 2163-2174.

Lamarche, V.C., Graybill, D.A., Fritts, H.C., Rose, M.R., 1984. Increasing atmospheric carbon dioxide: tree ring evidence for growth enhancement in natural vegetation. Science 225, 10191021.

Lebourgeois, F., Becker, M., Chevalier, R., Dupouey, J.-L., Gilbert, J.-M., 2000. Height and radial growth trends of Corsican pine in western France. Can. J. For. Res. 30, 712-724.

Lindström, M.J., Bates, D.M., 1990. Nonlinear mixed effect models for repeated measures data. Biometrics 46, 673-687.

Martin-Benito, D., Gea-Izquierdo, G., del Rio, M., Canellas, I., 2008. Long-term trends in dominant-height growth of black pine using dynamic models. For. Ecol. Manag. 256, 12301238.

Mäkinen, H., 1998. The suitability of height and radial increment variation in Pinus sylvestris (L.) for expressing environmental signals. For. Ecol. Manag. 112, 191-197.

Mäkinen, H., Nojd, P., Isomaki, A., 2002. Radial, height and volume increment variation in Picea abies (L.) Karst. stands with varying thinning intensities. Scand. J. For. Res. 17, 304-316.

McKenzie, H., Hawke, A., 1999. Growth response of Eucalyptus regnans dominant trees to thinning in New Zealand. N.Z. J. For. Sci. 29, 301-310.

Moisselin, J.M., Schneider, M., Canellas, C., Mestre, O., 2002. Climatic change in France over the 
20th century. Study of long-term homogenised time series of temperature and rainfall (in French). La Météorologie 38, 45-56.

Monserud, R.A., 1986. Time-series analyses of tree-ring chronologies. For. Sci. 32, 349-372.

Monserud, R.A., Sterba, H., 1996. A basal area increment model for individual trees growing in even- and uneven-aged stands in Austria. For. Ecol. Manag. 80, 57-80.

Mormiche, A., 1981. Silviculture and stand management (in French), in: Teissier du Cros, E. (Ed.), Le Hêtre, INRA, Paris, pp. 293-303.

Neumann, U., Rohle, H., 2002. Radial and height increment of Norway spruce (Picea abies (L.) Karst.) in the mountains of Saxony. Forstarchiv 73, 171-178.

Ott, E., 1978. Dependence of radial increment and top height in Norway spruce and European larch on altitude and aspect in Lotschental, Switzerland. Schweizerische Zeitschrift fur Forstwesen $129,169-193$.

Pardé, J., 1981. From 1882 to 1976/80. The thinning experiment plots of common beech in the State forest of Haye (Meurthe-et-Moselle) (In French). Revue Forestière Française 33, 41-64.

Peltola, H., Kilpeläinen, A., Sauvala, K., Räisänen, T., Ikonen, V.-P., 2007. Effects of early thinning regime and tree status on the radial growth and wood density of Scots pine. Silva Fennica 41, 489-505.

Pienaar, L.V., Shiver, B. D., 1984. The effect of planting density on dominant height in unthinned slash pine plantations. For. Sci. 30, 1059-1066.

Pinheiro, J.C., Bates, D.M., 2000. Mixed-effects models in S and S-PLUS. Springer-Verlag, NewYork.

Piovesan, G., Biondi, F., Di Filippo, A., Alessandrini, A., Maugeri, M., 2008. Drought-driven growth reduction in old beech (Fagus sylvatica L.) forests of the central Apennines, Italy Glob. Change Biol. 14, 1-17.

Polge, H., 1981. The influence of thinnings on the growth constraints of beech (in French). Ann. For. Sci. 38, 407-423. 
Ryan, M.G., Binkley, D., Fownes, J.H., 1997. Age-related decline in forest productivity: pattern and process. Adv. Ecol. Res. 27, 214-262.

Shapochkin, M.S., 1982. Patterns of distribution of radial increment by stem height in stands of Larix gmelinii. Lesnoe Khozyaistvo 4, 41-43.

Skovsgaard, J.P., Vanclay J.K., 2008. Forest site productivity: a review of the evolution of dendrometric concepts for even-aged stands. Forestry 81, 13-31.

Smith, F.W., Long, J.N., 2001. Age-related decline in forest growth: an emergent property. For. Ecol. Manag. 144, 175-181.

Spiecker, H., 1999. Growth trends in European forests - do we have sufficient knowledge?, in: EFI (Ed.), Causes and Consequences of Accelerating Tree Growth in Europe, EFI Proc. No. 27, pp. 157-169.

Spiecker, H., Mielikäinen, K., Köhl, M., Skovsgaard, J.P. (Eds.), 1996. Growth Trends in European Forests. Springer, Berlin Heidelberg.

Untheim, H., 1996. Has site productivity changed? A case study in the eastern Swabian Alb, Germany, in: Spiecker, H., Mielikäinen, K., Köhl, M., Skovsgaard, J.-P. (Eds.), Growth Trends in European Forests, Research Report No. 5, Springer, Berlin-Heidelberg, pp. 133147.

Wykoff, W.R., 1990. A basal area increment model for individual conifers in the northern Rocky Mountains. For. Sci.. 36, 1077-1104.

Zeide, B., 1993. Analysis of growth equations. For. Sci. 39, 594-616. 